
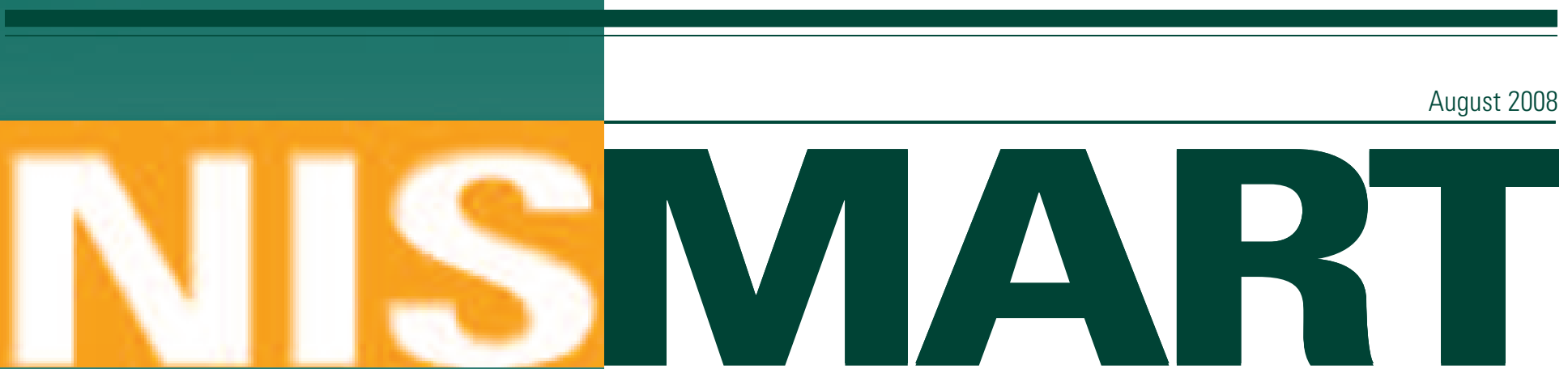

National Incidence Studies of Mi ssing, Abducted, Runaway, and Thrownaway Children

Office of Justice Programs

Innovation • Partnerships • Safer Neighborhoods www.ojp.usdoj.gov

\section{Sexually Assaulted Children: National Estimates and Characteristics}

\author{
David Finkelhor, Heather Hammer, and \\ Andrea J. Sedlak
}

This series of Bulletins summarizes findings from the Second National Incidence Studies of Missing, Abducted, Runaway, and Thrownaway Children (NISMART-2). The main purpose of the series is to provide a clear picture of how many children become missingand why. Bulletins in the series offer national estimates of missing children based on surveys of households, juvenile residential facilities, and law enforcement agencies. The Bulletins also present statistical profiles of these children, including their demographic characteristics and the circumstances of their disappearance. In addition, the series offers analyses of selected special topics, based on NISMART-2 data.

This Bulletin, the seventh in the NISMART-2 series, addresses a special topic: sexually assaulted children. The Bulletin provides information on the estimated number and characteristics of children who were sexually assaulted in the United States in 1999, based on NISMART-2 interviews with victims and their families. The estimates are derived from two components of the Second National Incidence Studies of Missing, Abducted, Runaway, and 
Thrownaway Children (NISMART-2): the National Household Survey of Adult Caretakers and the National Household Survey of Youth. These surveys were conducted during 1999 and reflect a 12-month period. Because the vast majority of cases reported were concentrated in 1999, the annual period referred to in the Bulletin is 1999.

\section{Key Findings}

In 1999 , an estimated 285,400 children were victims of a sexual assault ${ }^{1}$ and 35,000 were victims of some other type of sex offense.

An estimated 44 percent of the child victims of sexual assault and other sex offenses experienced an act of sexual penetration.

Sexual assault victims were disproportionately female (89 percent) and ages 12 to 17 (81 percent).

Most (95 percent) of the sexual assault victims were assaulted by a male. Almost three-fourths (71 percent) were assaulted by someone they were acquainted with or knew by sight; 18 percent were assaulted by a complete stranger, 10 percent by a family member.

- Twenty-nine percent of the sexual assault victims were assaulted by youth age 17 or younger.

- Police were contacted in regard to only 30 percent of the sexually assaulted children.

\section{Background: Availability of Data on Sexually Assaulted Children}

Sexual assaults against children are among the most highly publicized serious crimes. However, accurate and complete national estimates of their incidence have not been readily available.

The nation's most widely used crime statistics, the Federal Bureau of Investigation's annual report on crimes reported to police (FBI, 2001), do not differentiate sexual assaults against juveniles from those against adults, so this frequently cited source cannot be used to count juvenile victims of sexual assault. However, a reanalysis of the FBI's National Incident-Based Reporting System (NIBRS) data from 12 states for 1991-96 indicates that in one-third of all sexual assaults reported to law enforcement, the victim was younger than age 12 (Snyder and Sickmund, 1999:291.

The National Child Abuse and Neglect Data System (NCANDS), which is based on reports from child protective agencies in participating states, provides annual counts of incidents of child sexual abuse. However, NCANDS is far from comprehensive because the agencies providing these reports investigate offenses committed primarily by caretakers (U.S. Department of Health and Human Services, 2001). Thus, NCANDS excludes a substantial number of the sex offenses against juveniles, especially those committed by nonfamily members.

NIBRS and NCANDS share another important limitation as sources of information about sexually assaulted children. These official sources have been found to underrepresent the incidence of sexual assault because victims tend to underreport these events to law enforcement and other agencies (Finkelhor, 1994).

The National Crime Victimization Survey (NCVS), which interviews victims who did not report the crime to police in addition to those who did, provides information that is not available from police data (U.S. Department of Justice, 2000). However, NCVS underestimates the incidence of sexual assaults against children because it does not collect reports on crimes against children younger than 12-an important age group for estimates of sexual assault.

Because of these limitations, many of the most frequently cited estimates about child sexual assault have come from adult retrospective surveys (Bolen, 2001). These studies have other limitations. For example, it has generally been found that crime victimization recall deteriorates over time (Skogan, 1986). Moreover, adult retrospective reports cannot readily provide single-year incidence rates, which are the usual format in which crime victimization statistics are displayed. In addition, adult retrospective statistics reflect the experience of the previous, not the current, generation and do not easily allow for the measurement of trends.

Because Congress found that many missing children are at risk of sexual exploitation (42 U.S.C. 5771 Sec. 402) and because sexual assault is often the motive for nonfamily abduction, NISMART-2 included screening 
questions and interview sections designed to allow counts of sexual assaults. This Bulletin reports the sexual assault findings.

\section{Methodology}

The sexual assault estimates in this Bulletin are based on a nationally representative sample of children. The information on victimizations for this sample was obtained through proxy interviews with caretakers (for children ages $0-17$ ) and through interviews with the victims themselves (for children ages 10-17), conducted in 1999 as part of the NISMART-2 National Household Surveys of Adult Caretakers and Youth. The surveys used computer-assisted telephone interviewing methodology to collect information from a national probability sample of households.

Interviews were completed with 16,111 adult primary caretakers. The total number of children in the

\section{NISMART-2 Definitions}

\section{Rape and Sexual Assault}

\section{Rape}

Rape is forced sexual intercourse, meaning vaginal, anal, or oral penetration, including penetration by a foreign object and oral sex, where "force" includes both psychological coercion (threat) as well as physical force. Forced penetration occurs if the offender penetrates the victim or the victim is forced to penetrate the offender (as would be the case when the offender performs oral sex on a male victim). Additionally, NISMART-2 counts any situation where respondents described the situation with the term rape, and actual penetration (including oral sex) was reported in the subsequent questions that asked about penetration.

\section{Attempted Rape}

An attempted rape is an incident in which the perpetrator intends to force the victim to have sexual intercourse or oral sex, including verbal threats of rape, but the perpetrator does not penetrate the victim or successfully engage in oral sex.

NISMART-2 counts an incident as an attempted rape if there is any mention of the term "attempted rape" or "tried to [sex act that would involve penetration, like 'make me suck him']" or any "tried to," "attempted," or "make me" expression that strongly implies intercourse, like "make me sleep with him." Additionally, NISMART-2 counts any situation where respondents described the situation with the term rape, but actual penetration (including oral sex) was not reported in the subsequent questions that asked about penetration.

\section{Sexual Assault}

Sexual assault is separate from rape or attempted rape and is a mutually exclusive category. Sexual assaults involve unwanted sexual contact and must include the use or attempted use of force or threat. Unwanted sexual contact occurs when the perpetrator touches the child's private parts (defined as breasts, genitals, and buttocks) on skin or on top of clothes or when the child is forced or coerced to touch the perpetrator's private parts on skin or on top of clothes. Any mention of unwanted touching, under or over clothing, of private parts counts as unwanted sexual contact in NISMART2. "Unwanted" is to be broadly determined from the context of the respondent's remarks, including signs of being upset about the episode or agreement with any of the negative question items (e.g., "unwanted sex" or "attempted assault") in regard to it.

\section{Attempted Sexual Assault}

An attempted sexual assault is an unsuccessful attempt at unwanted sexual contact that is not an attempted rape and does not actually involve any unwanted sexual contact. An attempted sexual assault can occur only with the use or attempted use of force or threat. An attempted sexual assault includes any mention of the term "attempted or tried to" in conjunction with any sexual assault, molestation, or sexual abuse that is not classified as an attempted rape. If any touching of sexual areas actually occurs, then the incident is an actual rather than attempted sexual assault.

\section{Related Definitions}

Force, Attempted Force, or Threat of Force

Any action of grabbing, pushing, restraining, hitting, kicking, chasing, surrounding, knocking down, tripping, holding, throwing objects, or displaying a weapon is considered as using force in the context of a sex-related crime. These definitions include the use of physical force to dislodge or remove the victim's clothing. Any attempt to engage in these actions or any threat of engaging in these actions is considered as attempted force or threat of force and is sufficient to classify an incident as involving force.

\section{Noncontact Sex-Related Crimes}

Noncontact sex-related crimes include incidents of voyeurism and exhibitionism that are not already classified as rapes, attempted rapes, sexual assaults, or attempted sexual assaults. Voyeurism is the unwanted viewing of the child's private parts. Exhibitionism is the unwanted and intentional display of the offender's private parts to the child. 
households of respondents in the Household Survey sample was 31,787 . Each primary caretaker who completed an interview was asked for permission to interview one randomly selected youth in the household between the

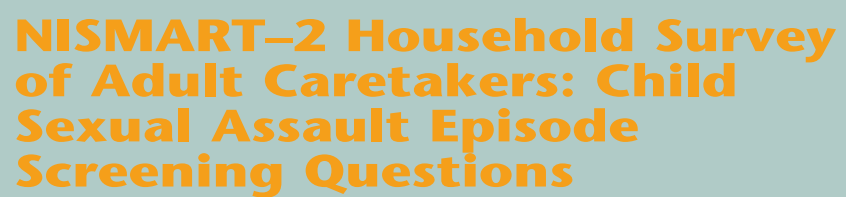

Questions 13-16 initiate a sexual assault followup interview.

(13) Was there any time when anyone tried to sexually molest, rape, attack, or beat up [this child/any of these children]?

(14) In the past 12 months, has anyone attacked or threatened [this child/any of these children] in any of these ways:

- With any weapon, for instance, a gun or knife;

- With anything like a baseball bat, frying pan, scissors, or stick;

- By something thrown, such as a rock or bottle;

- Including any grabbing, punching, or choking;

- Any rape, attempted rape, or other type of sexual attack;

- Any face-to-face threats;

- Any attack or threat or use of force by anyone at all?

Something that happens to some children these days is that adults or other youth try to force or trick them into doing something sexual. This includes trying to touch the child's private parts or trying to make the child touch or look at the other person's private parts. Children report that these kinds of things happen with people they know well or trust, like teachers or relatives.

(15) In the past 12 months, has there been a time when an older person, like an adult, an older teenager, or a babysitter, deliberately touched or tried to touch your child's private parts or tried to make your child touch or look at their private parts, when your child didn't want it?

(16) [Has/have] [this child/any of these children] been forced or coerced to engage in unwanted sexual activity by someone [he/she/they] didn't know before, a casual acquaintance, or someone [he knows/she knows/they know] well? ages of 10 and 18. Permission was obtained for 60 percent of the selected youth, yielding 5,015 youth interviews. ${ }^{2}$

The NISMART-2 Household Surveys were designed to screen for sexual assaults that met the study definitions (see sidebar on page 3). Adult caretakers were asked four screening questions (see sidebar on this page); the screening questions asked of youth were essentially the same. If the answer to any of the questions was "yes," the following specific questions were asked to confirm the episode.

During this episode, was the child sexually abused or molested?

During this episode, was there an attempt to sexually abuse or molest the child?

Then, if the episode was confirmed, the following questions were asked to collect the detailed information used to categorize the type of sexual assault:

Did the perpetrator touch the child's private parts in any way?

Did the perpetrator get the child to touch his/her private parts in any way?

Did the perpetrator actually put some part of his/her body or something else inside of the child?

Did the perpetrator try to put some part of his/her body or something else inside of the child?

Did the perpetrator actually put his/her mouth on the child's private parts, or get the child to put his/her mouth on the perpetrator's private parts ${ }^{3}$

Youth and adults in the same household could potentially disclose the same episode; when this happened, the child was counted only once. Children who were sexually victimized on different occasions because of multiple episodes, including different victimizations disclosed by the youth and caretaker, were counted only once. In developing national estimates of sexually assaulted children, data from both the youth and adult interviews were weighted to reflect the Census-based population of children. For additional methodological details, see OJJDP's NISMART-2 Household Survey Methodology Technical Report (Hammer and Barr, forthcoming). 


\section{Results}

An estimated 285,400 children ages 17 and younger experienced a sexual assault in 1999 (table 1), a rate of about 4.1 victims per 1,000 children in the U.S. population. Of these, 141,400 children experienced a rape (defined in the study as anal, oral, or vaginal penetration). An additional 60,400 experienced an attempted rape, and 55,900 were victims of a sexual assault that did not involve penetration. Another 27,600 experienced an attempted sexual assault (i.e., the perpetrator did not actually touch the child's sexual areas). Together, these four categories total an estimated 285,400 children who were victims of actual and attempted rapes and other actual and attempted sexual assaults, referred to collectively as "sexual assaults" in the analysis that follows. An additional 35,000 children who were victims of other sex offenses not typically defined as sexual assaults (primarily acts of exhibitionism or voyeurism without actual physical contact or force) have been excluded from the tables that follow because the numbers in this category were too small to analyze separately with any degree of reliability.

\section{Characteristics of Victims}

Females constituted the vast majority ( 89 percent) of sexual assault victims (table 2). Juveniles ages 12-17 made up 81 percent of the victims; older teenagers (ages 15-17) were disproportionately represented (54 percent of all victims compared with 17 percent of the general child population). Victimization of whites and blacks was proportionate to their percentages in the general child population. Hispanics constituted 9 percent of victims, compared with 16 percent of the child population.

\section{Characteristics of Perpetrators}

Twenty-three percent of the victims were assaulted by more than one perpetrator; these assaults were classified according to the characteristics of the perpetrator most closely related to the victim (table 3 ).

Ten percent of all victims were assaulted by a family member, including 4 percent who were assaulted by their father and 5 percent by a brother or other relative.
Most of the children (64 percent) were assaulted by an acquaintance, including 4 percent who were assaulted by an authority figure or a caretaker. Twenty-five percent of the victims were assaulted by a stranger, including someone the child knew by sight but not on a personal basis.

For 29 percent of victims, the assailant was age 17 or younger, including a small number of assailants younger than age 12. Forty-four percent of victims were assaulted by an adult younger than age 30 , and about a fifth by someone 30 or older. The vast majority (95 percent) of the victims were assaulted by a male.

\section{Characteristics of Assaults}

Fourteen percent of the victims were assaulted in their own home and another 38 percent were assaulted in someone else's home (table 4). Almost a fourth (23 percent) of the victims were assaulted in a public area. Cars and vehicles were the assault site for 9 percent of the victims, work locations for 6 percent. Victims for whom information on assault duration was available were about equally divided between incidents lasting less than an hour and incidents lasting an hour or longer. Ten percent of the victims were assaulted by someone using a weapon. For 23 percent of victims, the sexual assault took place during the course of a nonfamily or family abduction. ${ }^{4}$ Seventeen percent of victims were injured.

For 31 percent of the victims, the assault occurred in the summer. Children were more likely to be victimized on Friday or Saturday compared to other days and least likely to be victimized in the morning compared to the afternoon, evening, or night.

\section{Police Contacts}

Police were contacted about the sexual assault for only 30 percent of the victims (table 5). The most common reason for not contacting the police was that the victimized youth did not want the caretakers to find out about the episode because of circumstances they probably would have disapproved of, such as the youth's being under the influence of drugs or alcohol at the time of the assault. 


\section{NISMART}

Table 1: Estimates of Sexual Offenses Against Children

\begin{tabular}{lccc} 
Type of Incident & Estimate & $\begin{array}{c}\text { 95\% Confidence } \\
\text { Interval }\end{array}$ & Percent \\
\hline Rape & 141,400 & $71,800-211,000$ \\
$\quad$ Attempted rape & $60,400^{*}$ & $13,400-107,400$ \\
Other sexual assault & 55,900 & $<100-133,100$ & $19 *$ \\
$\quad$ Attempted other sexual assault & $27,600^{*}$ & $3,300-51,900$ & $\mathbf{1 7}$ \\
All rape and other sexual assault & $\mathbf{2 8 5 , 4 0 0}$ & $\mathbf{2 0 0 , 4 0 0 - 3 7 0 , 3 0 0}$ \\
Other sex offense & 35,000 & $10,200-59,800$ \\
All rape, other sexual assault, & 320,400 & $\mathbf{2 3 1 , 9 0 0 - 4 0 8 , 9 0 0}$ \\
and other sex offense & & & $\mathbf{1 0 0}$
\end{tabular}

Notes: For definitions of types of incidents, see page 3. Estimates are rounded to the nearest 100 and may not sum to the total.

* Estimate is based on too few sample cases to be reliable. Another study with the same sample size and methodology might produce a very different estimate.

\section{Table 2: Characteristics of Sexually Assaulted Children}

Sexual Assault Victims

$(n=285,400)$

\section{Characteristic of Child}

Estimate

Percent

Percent of U.S. Child Population

\section{Gender}

Female

252,700

89

49

Male

32,700

11

51

Age (years)

$\begin{array}{lrrr}0-5 & 12,300^{*} & 4^{*} & 33 \\ 6-8 & 9,800^{*} & 3^{*} & 17 \\ 9-11 & 30,500 & 11 & 17 \\ 12-14 & 77,900 & 27 & 17 \\ 15-17 & 154,800 & 54 & 17\end{array}$

\section{Race/ethnicity}

White, non-Hispanic

182,000

64

63

Black, non-Hispanic

52,200

18

16

Hispanic

$26,500 *$

9*

16

Other

23,500 *

8*

6

No information

$1,200^{*}$

$<1^{*}$

Notes: Estimates are rounded to the nearest 100 and may not sum to the total. Percents may not sum to 100 because of rounding. Gender, age, and race distributions for the U.S. population were based on the average monthly estimates of the population ages 0-17 for 1999 (U.S. Census Bureau, 2000).

*Estimate is based on too few sample cases to be reliable. Another study with the same sample size and methodology might produce a very different estimate. 
Table 3: Characteristics of Sexual Assault Perpetrators

\begin{tabular}{|c|c|c|}
\hline \multirow{2}{*}{$\begin{array}{l}\text { Characteristic of } \\
\text { Perpetrator }\end{array}$} & \multicolumn{2}{|c|}{$\begin{array}{l}\text { All Sexual Assault Victims } \\
\qquad(n=285,400)\end{array}$} \\
\hline & Estimate & Percent \\
\hline \multicolumn{3}{|l|}{ More than one perpetrator } \\
\hline Yes & 64,800 & 23 \\
\hline No & 216,500 & 76 \\
\hline No information & $4,000 *$ & $1 *$ \\
\hline \multicolumn{3}{|l|}{ Identity of main perpetrator } \\
\hline Family member & 27,200 & 10 \\
\hline Father & $12,600 *$ & $4^{*}$ \\
\hline Brother & $5,700 *$ & $2^{*}$ \\
\hline Other relative & $9,000^{*}$ & $3^{*}$ \\
\hline Acquaintance & 183,200 & 64 \\
\hline Child's friend or acquaintance & 148,100 & 52 \\
\hline Family friend or acquaintancet & $23,300 *$ & $8^{*}$ \\
\hline Authority or caretaker & $11,800^{*}$ & $4^{*}$ \\
\hline Stranger & 72,400 & 25 \\
\hline Known only by sight & $20,200 *$ & $7 *$ \\
\hline Complete stranger & 52,200 & 18 \\
\hline No information & $2,500^{*}$ & $1^{*}$ \\
\hline \multicolumn{3}{|l|}{ Main perpetrator's age } \\
\hline 12 or younger & $12,000 *$ & $4^{*}$ \\
\hline $13-17$ & 71,700 & 25 \\
\hline $18-29$ & 124,700 & 44 \\
\hline $30-39$ & $23,100^{*}$ & $8^{*}$ \\
\hline $40-49$ & $21,600 *$ & $8^{*}$ \\
\hline $50+$ & $8,100^{*}$ & $3^{*}$ \\
\hline No information & $24,100^{*}$ & $8^{*}$ \\
\hline \multicolumn{3}{|l|}{ Main perpetrator's gender } \\
\hline Male & 272,500 & 95 \\
\hline Female & $10,300 *$ & $4^{*}$ \\
\hline No information & $2,500 *$ & $<1 *$ \\
\hline
\end{tabular}

Notes: Estimates are rounded to the nearest 100 and may not sum to the total. Percents may not sum to 100 because of rounding.

*Estimate is based on too few sample cases to be reliable. Another study with the same sample size and methodology might produce a very different estimate.

tIncludes neighbors Table 4: Characteristics of Child Sexual
Assaults

\begin{tabular}{lc} 
Characteristic of & $\begin{array}{c}\text { Percent of All Sexual } \\
\text { Assault Victims } \\
\text { Episode }\end{array}$ \\
\hline
\end{tabular}

Location

Own home 14

Other home 38

Car or other vehicle 9

Work $6^{*}$

Public area 23*

Other location $\quad 8^{*}$

\section{Duration}

Less than 1 hour 42

1 hour or longer $\quad 46$

No information 12

Coercive elements and harm

Perpetrator used weapon 10*

Child was abducted 23

Child was injured 17

\section{Season}

Winter 21

Spring 28

Summer 31

Fall 20

Day of week

Monday through Thursday $\quad 12$

Friday 36

Saturday $17^{*}$

Sunday $4^{*}$

No information 31

Time of day

Morning 2*

Afternoon 27

Evening 30

Night 32

No information $\quad 9^{*}$

Note: Percents may not sum to 100 because of rounding.

* Estimate is based on too few sample cases to be reliable. Another study with the same sample size and methodology might produce a very different estimate. 
Table 5: Police Contact for Child Sexual Assaults

\begin{tabular}{lc} 
Police Contact for & $\begin{array}{c}\text { Percent of All Sexual } \\
\text { Assault Victims } \\
\text { Episode }\end{array}$ \\
\hline
\end{tabular}

\section{Any police contact}

Yes

30

No

70

\section{Why police were not contacted}

Child did not want caretaker

to find out about assault or

caretaker was told too long

after assault occurred

59

Not serious enough

Child wanted to protect

perpetrator

Other reason

No information

Note: For the responses on why police were not contacted, percents are computed from a baseline of 198,600 - the number of children with no police contact.

* Estimate is based on too few sample cases to be reliable. Another study with the same sample size and methodology might produce a very different estimate.

\section{Implications}

\section{Comparisons to Other Data Sources}

To obtain a more comprehensive estimate of the incidence of child sexual assault than was previously available, this study used national samples of caretakers and youth to gather information about the victimization experiences of children of all ages. As a result, the NISMART-2 estimate of 285,400 children sexually assaulted in 1999 is significantly higher than estimates available from other sources. Two major sources mentioned earlier in this Bulletin produced counts or estimates of 82,000 (NCANDS) and 72,300 (NCVS) for 1999.

As mentioned previously, NCANDS, a frequently used source of statistics on sexual assaults against children, is based on reports from child protective agencies. Because it excludes most sex crimes against children committed by noncaretakers, and because it includes only cases reported and substantiated by child protection authorities, NCANDS is not comprehensive and, not surprisingly, produced a count much lower than the NISMART-2 estimate.

The NCVS estimates, which are based on interviews with victims, are also substantially lower than the NISMART-2 estimates. Differences in definition are unlikely to account for this discrepancy, because the researchers made a conscientious effort to align NISMART-2 definitions with NCVS definitions (see sidebars on pp. 3 and 81 .

Two major differences in methodology, however, likely contributed significantly to the discrepancy in estimates. First, NCVS obtains victimization information from direct interviews with persons age 12 and older, whereas

\section{Sexual Assault}

Sexual assault includes a wide range of victimizations, separate from rape or attempted rape. These crimes include attacks or attempted attacks generally involving (unwanted) sexual contact between victim and offender. Sexual assaults may or may not involve force, such as grabbing or fondling, and may also include verbal threats.

\section{Attempted Sexual Assault}

An attempted sexual assault is an unsuccessful attempt at unwanted sexual contact, including verbal threat of sexual assault, that is not an attempted rape and does not involve any actual unwanted sexual contact.

Source: U.S. Bureau of Justice Statistics, National Crime Victimization Survey, 1992-1998 Codebook for Parts 53-56, Washington, DC: U.S. Department of Justice, Office of Justice Programs, Bureau of Justice Statistics, 2000 
NISMART-2 interviewed children as young as 10. Second, in addition to information collected directly from the sample of youth age 10 or older, NISMART-2 also collected proxy information from caretakers for children of all ages. Thus, NISMART-2 counted two kinds of sexual assault episodes that NCVS methodology excludes: (1) assaults of children younger than 12; and (2) assaults of children age 12 or older who did not disclose the incident themselves but whose caretaker knew of and disclosed the incident. Both of these factors would make the NISMART-2 estimates higher than the NCVS estimates.

Additional methodological differences between NISMART-2 and NCVS cannot be specifically quantified but may have influenced the discrepancy between the two sets of estimates. First, NISMART-2 used a single interview to ask about a 1-year time period, whereas NCVS interviews participants every 6 months over a 3-year period (and so is better able to assure that assaults that occurred outside a 1-year estimating period have not been mistakenly telescoped into the estimate). Second, some NCVS interviews are conducted in person, whereas NISMART-2 conducted all interviews by telephone. Third, the NCVS survey has a very explicit crime focus, which may inhibit reports about events (such as sexual assaults by acquaintances and other youth) that respondents may not conceptualize as crimes. ${ }^{5}$ Finally, although the NCVS and NISMART-2 definitions of rape, attempted rape, sexual assault, and attempted sexual assault are similar, the interviews use different questions to determine if an episode qualifies. All of these factors may account for lower numbers in the NCVS estimates.

To examine the discrepancy between NISMART-2 and NCVS controlling for as many methodological differences as possible, the number of NISMART-2 children who were sexually assaulted was re-estimated using only, as in NCVS, the self-reports of youth ages 12-17 at the time of the assault. ${ }^{6}$ This comparison between the NISMART-2 and NCVS sexual assault estimates for 1999 , based entirely on self-reports from youth ages $12-17$, finds that the NISMART-2 estimate of sexually assaulted children is still at least three times greater than the NCVS estimate: 219,700 vs. $72,300{ }^{7}$

The difference between NISMART-2 and NCVS estimates might be even greater if another important methodological difference could be taken into consideration. NISMART-2 counted children with multiple sexual assaults only once, whereas NCVS counts each episode. Thus, the NISMART-2 estimate could potentially be even higher had the survey counted assaults rather than victims.

\section{Indications of Underreporting}

Even though NISMART-2 produced higher estimates than other data sources, many indications of underreporting suggest that the NISMART-2 estimates are undercounts. For example, more than half of the youth who were interviewed after their caretaker disclosed the youth's victimization did not disclose the assault in their own interview. As a result, one would expect that a considerable number of additional youth whose caretakers did not know about the assault also failed to disclose. Additionally, the accuracy of the proxy reports by caretakers could be influenced by their not wanting to disclose the abuse to a telephone interviewer. The latter situation would have a proportionally larger effect on underreporting for victims younger than 10, for whom caretaker proxy reports were the only source of information.

For these reasons, the distribution of sexual assaults in this sample is skewed in comparison to the distributions obtained from many adult retrospective surveys (Finkelhor and Baron, 1986). The sample contains proportionately fewer assaults by family members and against younger children than usually appear in such retrospective surveys. Because of ongoing intimidation and family loyalty, children typically find it difficult to disclose family abuse. Younger children are especially reluctant to disclose family abuse and, as noted above, the experience of children younger than 10 could only be represented in the NISMART-2 survey if their caretaker knew about it and disclosed it. Thus, younger children who have been sexually abused by family members are the type of abuse victim most likely to be underreported in NISMART-2.

\section{Methodological Innovations}

It may be inherently impossible to get a complete and unbiased accounting of all child sexual assaults close to the time they occur. Nevertheless, the current study suggests that a much clearer picture of the problem's full dimension can be revealed by including caretakers as 
proxy reporters and by trying to assess victimization across the whole age range of childhood. Table 6 disaggregates the NISMART-2 estimate of sexually assaulted children by source of information (self-reports for children ages 12-17 and 10-11, proxy reports for children ages 12-17 and younger than 12). Proxy reports accounted for 34 percent of the estimate (18 percent for children ages 12-17 and 16 percent for children younger than 12). Reports concerning children younger than 12 comprised 18 percent of the estimate; most of these reports were from caretakers, but 2 percent were from self-reports of children age 10 or 11 .

Using proxy interviews to obtain information on crime victimization and other sensitive topics has never been a preferred methodology and has sometimes yielded poor results. However, the method certainly merits further investigation as a means of studying sexual assaults of younger children, given the seriousness of these incidents, the importance of getting good epidemiological information about them, and the likelihood that caretakers are most aware of their children's experiences when the children are young. A recent comparison of proxy and self-reports of victimization among preadolescent children yielded evidence that such a mixed approach can be useful (Finkelhor et al., 2005).

In addition to these methodological innovations, NISMART-2 added two new screening questions to those that NCVS uses:
These new screening questions accounted for 29,100 children, or about 10 percent of the total estimate of 285,400 sexually assaulted children.

\section{Historical Trends}

NISMART-1, which estimated missing children in 1988, did not collect information about sexual assault in a way that would allow comparison with NISMART-2 to examine historical trends. However, data from other sources have shown that sexual assault declined during the 1990s. According to NCANDS, substantiated sexual abuse cases identified by child protective agencies declined 39 percent between 1993 and 1999 (Jones and Finkelhor, 2001). NCVS data show a 56-percent decline between 1993 and 2000 in sexual assaults self-reported by youth ages 12-17 (Finkelhor and Jones, 2004).

\section{Conclusion}

Because child sexual abuse will continue to be a salient concern for law enforcement and the general public, there is a clear need to continue to track as accurately as possible its true incidence, trends, and the characteristics of victims and perpetrators. The NISMART-2 estimates of child sexual assault provide a benchmark for tracking future trends, and NISMART's interviews with adult caretakers and younger children suggest ways of measuring the incidence of sexual assault across the full spectrum of childhood.
Was there any time when anyone tried to sexually molest, rape, attack, or beat up [this child/any of these children]?

In the past 12 months, has there been a time when an older person, like an adult, an older teenager, or a babysitter, deliberately touched or tried to touch your child's private parts or tried to make your child touch or look at their private parts, when your child didn't want it?
Table 6: NISMART-2 Estimates of Sexually Assaulted Children, by Source of Information
Information Source

All victims

Self-report (victims ages 12-17)

Proxy report by caretaker (victims ages 12-17)

Self-report (victims ages 10-11)

Proxy report by caretaker (victims under age 12)
Estimate

285,400

181,400

51,300

$7,000 *$

45,700
Percent

100

64

18 $2^{*}$
Notes: Assaults disclosed by both youth and caretaker are counted as self-reports by the youth. Children younger than 10 were not interviewed; therefore, youth interviews could not disclose assaults that occurred before age 9. Estimates are rounded to the nearest 100 and may not sum to the total. Percents may not sum to 100 because of rounding.

*Estimate is based on too few sample cases to be reliable. Another study with the same sample size and methodology might produce a very different estimate. 


\section{Endnotes}

1. NISMART-2 definitions distinguish between rape and sexual assault (see page 3); the discussion in this Bulletin, however, generally uses "sexual assault" as an umbrella term to encompass actual and attempted rapes and other sexual assaults and attempted sexual assaults.

2. Among eligible households with children, the NISMART-2 cooperation rate was 80 percent and the response rate was 61 percent. Among youth for whom permission to interview was granted, the cooperation rate was 95 percent; the response rate for the youth survey overall was 35 percent $(.61 \star .60 \star .95)$. The American Association of Public Opinion Research (AAPOR) defines a response rate as the number of completed interviews with reporting units divided by the number of eligible reporting units in the sample; AAPOR defines the cooperation rate as the number of cases interviewed divided by the number of eligible units ever contacted (AAPOR, 2004). The NISMART-2 response rate and cooperation rate were computed with AAPOR formulas RR4 and COOP2, respectively.

3. This question was asked only if penetration was not indicated in response to the earlier question.

4. For definitions, see Finkelhor, Hammer, and Sedlak (2002) and Hammer, Finkelhor, and Sedlak (2002).

5. For further discussion of NCVS methodology, see Fisher and Cullen (2004).

6. The NCVS data for 1999 were also re-analyzed by restricting the estimate to sexual assaults experienced by victims ages 12-17 and computing 95-percent confidence intervals with Bureau of Justice Statistics procedures using generalized variance functions for 1999.

7. 95-percent confidence interval: 117,400-322,100

(NISMART-2) vs. 41,800-102,400 (NCVS).

\section{References}

American Association for Public Opinion Research (AAPOR). 2004. Standard Definitions: Final Dispositions of Case Codes and Outcome Rates for Surveys. 3d edition. Lenexa, KS: AAPOR.

Bolen, R.M. 2001. Child Sexual Abuse: Its Scope and Our Failure. New York: Kluwer Academic/Plenum Publishers.

Federal Bureau of Investigation. 2001. Crime in the United States, 1999: Uniform Crime Reports. Washington, DC: U.S. Department of Justice.

Finkelhor, D. 1994. Current information on the scope and nature of child sexual abuse. The Future of Children 4(2):31-53.
Finkelhor, D., and Baron, L. 1986. High-risk children. In A Sourcebook on Child Sexual Abuse, edited by D. Finkelhor. Beverly Hills, CA: Sage Publications.

Finkelhor, D., Hamby, S.L., Ormrod, R.K., and Turner, H.A. 2005. The JVQ: Reliability, validity, and national norms. Child Abuse and Neglect 29(4):383-412.

Finkelhor, D., Hammer, H., and Sedlak, A.J. 2002. Nonfamily Abducted Children: National Estimates and Characteristics. NISMART Bulletin. Washington, DC: U.S. Department of Justice, Office of Justice Programs, Office of Juvenile Justice and Delinquency Prevention.

Finkelhor, D., and Jones, L.M. 2004. Explanations for the Decline in Child Sexual Abuse Cases. Crimes against Children Bulletin. Washington, DC: U.S. Department of Justice, Office of Justice Programs, Office of Juvenile Justice and Delinquency Prevention.

Fisher, B.S., and Cullen, F.T. 2004. Measuring the sexual victimization of women: Evolution, current controversies, and future research. In Criminal Justice 2000, Volume 4: Measurement and Analysis of Crime and Justice, edited by D. Duffee. Washington, DC: U.S. Department of Justice, Office of Justice Programs, National Institute of Justice.

Hammer, H., and Barr, M.K. Forthcoming. NISMART-2 Household Survey Methodology Technical Report. Washington, DC: U.S. Department of Justice, Office of Justice Programs, Office of Juvenile Justice and Delinquency Prevention.

Hammer, H., Finkelhor, D., and Sedlak, A.J. 2002. Children Abducted by Family Members: National Estimates and Characteristics. NISMART Bulletin. Washington, DC: U.S. Department of Justice, Office of Justice Programs, Office of Juvenile Justice and Delinquency Prevention.

Jones, L., and Finkelhor, D. 2001. The Decline in Sexual Abuse Cases. Crimes against Children Bulletin. Washington, DC: U.S. Department of Justice, Office of Justice Programs, Office of Juvenile Justice and Delinquency Prevention.

Skogan, W.G. 1986. Methodological issues in the study of victimization. In From Crime Policy to Victim Policy: Reorienting the Justice System, edited by E.A. Fattah. Hampshire, UK: Palgrave Macmillan.

Snyder, H.N., and Sickmund, M. 1999. Juvenile Offenders and Victims: 1999 National Report. Washington, DC: U.S. Department of Justice, Office of Justice Programs, Office of Juvenile Justice and Delinquency Prevention.

U.S. Census Bureau. 2000. (NP-D1-A) Projections of the resident population by age, sex, race, and Hispanic origin: 
Office of Justice Programs

Office of Juvenile Justice and Delinquency Prevention

Washington, DC 20531

Official Business

Penalty for Private Use $\$ 300$

\section{References (continued)}

1999-2100. Washington, DC: Population Projections Program, Population Division.

U.S. Department of Health and Human Services, Administration on Children, Youth and Families. 2001. Child Maltreatment 1999. Washington, DC: U.S. Government Printing Office.

U.S. Department of Justice, Bureau of Justice Statistics. 2000. National Crime Victimization Survey, 1992-1998. Machinereadable data file. Ann Arbor, MI: Inter-University Consortium for Political and Social Research, National Archive of Criminal Justice Data. www.icpsr.umich.edu/NACJD/NCVS/index.html.

This Bulletin was prepared under grant number 95-MC-CX-K004 from the Office of Juvenile Justice and Delinquency Prevention, U.S. Department of Justice.

Points of view or opinions expressed in this document are those of the authors and do not necessarily represent the official position or policies of OJJDP or the U.S. Department of Justice.

The Office of Juvenile Justice and Delinquency Prevention is a component of the Office of Justice Programs, which also includes the Bureau of Justice Assistance; the Bureau of Justice Statistics; the Community Capacity Development Office; the National Institute of Justice; the Office for Victims of Crime; and the Office of Sex Offender Sentencing, Monitoring, Apprehending, Registering, and Tracking (SMART).

\section{Acknowledgments}

David Finkelhor, Ph.D., is Professor of Sociology and Director, Crimes against Children Research Center, University of New Hampshire, and Advisor to NISMART-2. Heather Hammer, Ph.D., is a Senior Study Director at the Temple University Institute for Survey Research, Philadelphia, PA, and Principal Investigator of NISMART-2. Andrea J. Sedlak, Ph.D., is Associate Director of Human Services Research at Westat, Inc.; Project Director of the NISMART-2 Unified Estimate, Juvenile Facilities Study, and Law Enforcement Study; and Advisor to the NISMART-2 Household Survey. The authors extend their appreciation to the many others who contributed to the NISMART-2 project and to Barbara Allen-Hagen, OJJDP NISMART-2 Program Manager, for her support and guidance.

\section{Other NISMART Publications}

National Estimates of Missing Children: An Overview Children Abducted by Family Members: National Estimates and Characteristics

Nonfamily Abducted Children: National Estimates and Characteristics

Runaway/Thrownaway Children: National Estimates and Characteristics

National Estimates of Children Missing Involuntarily or for Benign Reasons

National Estimates of Missing Children: Selected Trends, 1988-1999

NISMART Questions and Answers

All publications may be downloaded at OJJDP's Web site, www.ojp.usdoj.gov/ojjdp. 